\title{
Fluorescence In Situ Hybridization Studies of Sperm Aneuploidies in Infertile Men
}

\author{
Elena Moretti* and Giulia Collodel
}

\author{
Department of Biomedical Sciences, Applied Biology Section, Interdepartmental Centre for Research and Therapy of \\ Male Infertility, University of Siena, Italy
}

\begin{abstract}
Fluorescence in situ hybridization analysis, performed with chromosome specific DNA probes labeled with fluorochromes, is a simple and reliable tool for the indirect study of aneuploidies in interphase cells such as spermatozoa.

It is known that infertile male patients with poor sperm quality, due to different causes, produce cytogenetically abnormal spermatozoa despite a normal constitutional karyotype as a result of an altered intra-testicular environment that negatively affects the mechanisms controlling chromosome segregation during cell division. A particular subgroup of this category is composed of individuals with systematic sperm defects, characterized by an identical, specific alteration that affects the vast majority of their sperm population. Altered meiotic segregation has been described mainly in globozoospermia and in sperm with dysplasia of the fibrous sheath.

Moreover, we also considered sperm aneuploidies in the presence of somatic chromosome abnormalities: numerical chromosomal anomalies, such as the presence of an extra chromosome and structural chromosomal anomalies, including translocations and inversions. It is known that somatic chromosomal abnormalities are often associated with infertility and have definite consequences on the cytogenetic anomalies observed in spermatozoa.

Since individuals with abnormal semen parameters, also those that are carriers of a constitutional abnormal karyotype, make up the majority of intracytoplasmic sperm injection candidates, it is of great interest to study the chromosomal constitution of their spermatozoa.

The problem of the possible presence of aneuploidy in sperm from infertile men should be seriously considered due to the documented risk of the transmission of a chromosomal imbalance to offspring.
\end{abstract}

\section{INTRODUCTION}

Infertility is a significant problem that affects up to $15 \%$ of couples in the reproductive age [1]. Difficulties in reproduction have been associated with somatic chromosomal anomalies or with cytogenetic abnormalities found directly in the germ cells of infertile individuals with a normal constitutional karyotype.

Both of these categories generally show more or less severely compromised spermatogenesis leading to altered sperm parameters concomitant with an increase in the frequency of chromosome aneuploidy [2,3].

Meiosis is a process that includes two consecutive cells divisions, with a single DNA replication, leading to a reduction in the amount of genetic material. The first meiotic division involves primary spermatocytes (diploid) and consists of a pairing of homologous chromosomes in order to recombine genetic material and to produce new genetic combinations in the offspring; at anaphase, each homologous chromosome migrates to the cell poles to produce secondary spermatocytes. During the second meiotic division the chromatids of each chromosome migrate to cell poles to produce haploid spermatids. The spermatids are finally

*Address correspondence to this author at the Department of Biomedical Sciences, Applied Biology Section, University of Siena, Policlinico Le Scotte, Viale Bracci, 14, 53100 Siena, Italy; Tel: 39-0577-233539; Fax: 390577-233527; E-mail: moretti@unisi.it shaped in spermatozoa by means of spermiogenesis, a process characterized by the formation of the acrosome and the axoneme, by the change of the cellular profile and the relocation of organelles. If any of these steps fails to happen correctly, different kinds of chromosome abnormalities, such as aneuploidy and diploidy, can occur [4].

The possible consequences of sperm aneuploidies become clinically relevant with the advent of assisted reproductive techniques (ART), particularly with the introduction of intracytoplasmic sperm injection (ICSI), which gave rise to many concerns about its safety and about long term effects on offspring. ICSI bypasses all the natural barriers of the fertilization process, enabling sperm with abnormal morphology and motility and those that are not fully mature to fertilize the egg.

Since individuals with abnormal semen parameters make up the majority of ICSI candidates, it is of great interest to study the chromosomal constitution of their spermatozoa. During the past few years there has been an explosion in the information about chromosome abnormalities in human sperm and the meiotic events that induce these abnormalities. The chromosome constitution of human spermatozoa was studied for the first time in 1978 by Rudak et al. [5] using the ability of human spermatozoa to penetrate zonafree hamster oocytes, and subsequently by other groups [68]. This method provides precise sperm karyotypes, in which numerical and structural abnormalities can be assessed for 
each chromosome. However, sperm-hamster oocyte fusion is difficult and time-consuming, thus its use was limited to a few laboratories and it was never applied in a clinical setting.

Fluorescence in situ hybridization (FISH) technology is a useful option for estimating aneuploidy frequencies directly in interphase cells, such as spermatozoa [3]. FISH analysis is based on the hybridization of chromosome-specific DNA probes labeled with different fluorocromes to complementary DNA sequences on target chromosomes, and then on detection by means of an optical microscope equipped with a fluorescence apparatus and filters for the dyes that were used. Centromeric or locus specific probes can enumerate chromosomes in interphase nuclei and their use allows for the study of thousands of spermatozoa in a relatively short period of time. Two-color FISH is required for autosomes analysis and three-color FISH is necessary for the analysis of sex chromosomal aneuploidy in order to distinguish a diploid $\mathrm{XY}$ sperm (two autosomal signal, Fig. (1a, b) from a disomic one (one autosomal signal, Fig. (1c, d). FISH emerged as a fast, inexpensive and easy method to study sperm chromosomal constitution, and for this reason it has been included in the protocols for the study of infertile males in many laboratories around the world. It should be noted that FISH is an indirect method: fluorescent signals, rather than chromosomes, are scored. The limitations of FISH analysis consist in the impossibility to obtain a complete karyotype: the analysis only considers the chromosomes investigated and does not allow for the detection of chromosomal structural anomalies. New methods, such as single sperm typing and synaptonemal complex analysis, have provided valuable insight into the association between meiotic recombination and the production of aneuploid sperm [3]. Single sperm polymerase chain reaction is a difficult and time consuming technique that can be used in specific studies on recombination in particular areas of the genome. Meiotic analysis of the synaptonemal complex (SC) can be performed by means of immunofluorescence using antibodies able to visualize SC elements or DNA repair proteins such as MLH1, identifying the sites of meiotic exchange [3].

The first report on spermatozoa from infertile men analyzed by FISH was published in 1994 [9]. Since that time an increasing number of papers have illustrated FISH data in decondensed sperm nuclei in order to evaluate the incidence of aneuploidies and diploidies in infertile males with a normal karyotype. First of all, meiotic alterations were found in cases of severe oligoasthenoteratozoospermia (OAT) [4, $10,11]$. The risk of chromosomal aneuploidies was inversely correlated with sperm concentration and total progressive motility [12, 13]. Templado et al. [14] demonstrated an increase in sperm chromosome abnormalities in a selected group of patients with asthenoteratozoospermia and normal sperm concentration. At the same time the studies focused on the correlation between the incidence of chromosomal alterations and sperm morphology, sometimes also evaluated by transmission electron microscopy (TEM) [15-19].

Subjects showing systematic sperm defects [20] are a particularly interesting subgroup of infertile men with a normal constitutional karyotype. In these rare cases all the spermatozoa of a sterile individual are affected by only one
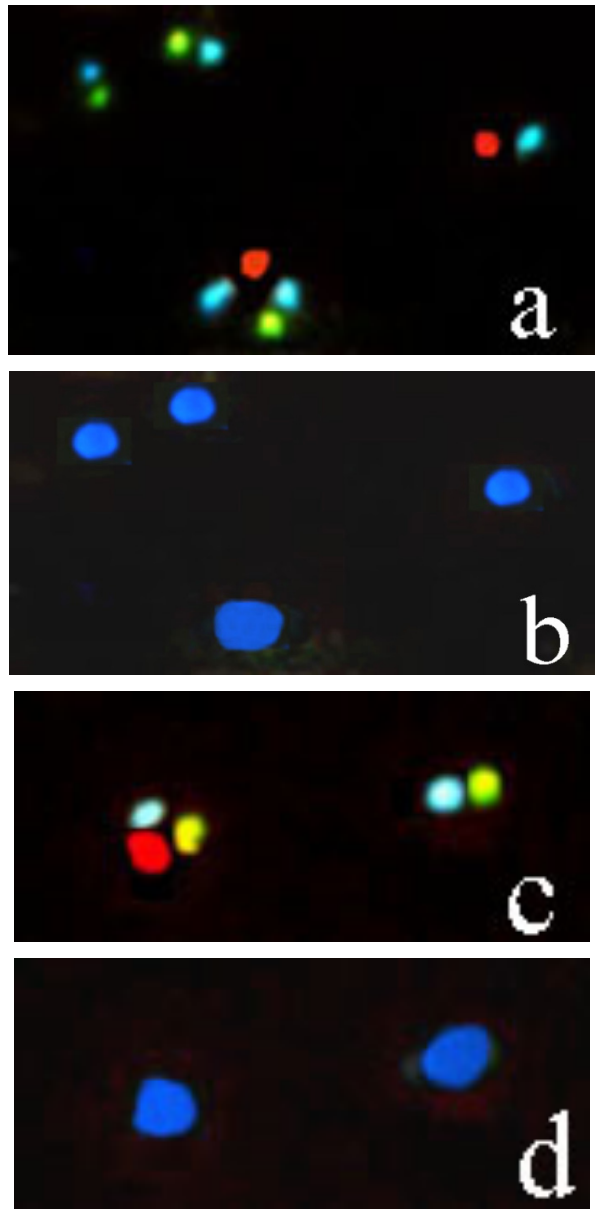

Fig. (1). Micrographs showing human sperm nuclei studied by FISH performed using probes (CEP, Chromosome Enumeration Probes, Vysis, IL, USA) for chromosomes 18 (aqua), X (green) and $\mathrm{Y}$ (red). A diploid sperm is characterised by a green $\mathrm{X}$ signal, a red $\mathrm{Y}$ signal and two aqua chromosome 18 signals (a); a disomic sperm shows a green $\mathrm{X}$ signal, a red $\mathrm{Y}$ signal and a single aqua chromosome 18 signal (c). Figs b-d represent the same spermatozoa after 4',6 Diamidino -2-phenylindole dihydrochloride (DAPI) staining.

identical, specific alteration. This alteration is not treatable and is present during the entire life of the subject. The spermatozoa of these patients will always be unable to naturally fertilize and their defects have been suspected of having a genetic origin $[20,21]$. The systematic sperm defects reported in the literature are: the "crater defect" [22], the "globozoospermia" [23], the "miniacrosome" [24], the "detached tail" $[25,26]$, the "Dysplasia Fibrous Sheath" (DFS) [27], the "Primary Ciliary Dyskinesia" (PCD) [28], the "9+0 axoneme" [29], and composed tail defects characterized by an abnormal mitochondrial helix associated with the presence of multiple axonemes and alternatively with the "absence of fibrous sheath" $[30,31]$ or lack of axoneme and outer dense fibers from the principal piece [32].

In regard to systematic sperm defects, few papers have reported aneuploidy and diploidy data in decondensed sperm nuclei concerning mainly globozoospermia, DFS and PCD [33-43]. 
Another field of investigation concerns the correlation between the presence of an abnormal lymphocyte karyotype and an increased incidence of sperm aneuploidy.

The most common karyotype alterations include numerical sex chromosome anomalies, such as the 47, XXY chromosome constitution in Klinefelter syndrome, or 47, $\mathrm{XYY}$ aneuploidy and balanced structural chromosomal reorganizations, such as Robertsonian translocations or reciprocal translocations which are found in $0.1 \%$ of newborns, or pericentric and paracentric inversions that are detected in $0.02 \%$ of newborns (with the exception of inversions affecting the heterochromatic regions of chromosomes 1,9 and 16, which are considered to be polymorphisms) [4]. Structural chromosomal anomalies, usually involving sex (4\%) and autosomal (1\%) chromosomes $[44,45]$, occur more frequently in infertile men than in the general population [46].

Since cytogenetic studies of spermatozoa have become possible, several groups have focused on the analysis of the meiotic behavior of specific chromosomal reorganizations and on the evaluation of balanced or unbalanced sperm in order to offer patients accurate reproduction advice. Many papers have reported the correlation between the presence of abnormal lymphocyte karyotype, mainly translocations, and an increased incidence of sperm aneuploidies [3, 12, 47-51]. Moreover, in patients with an altered somatic karyotype, the segregation of rearranged chromosomes could lead to missegregation of the chromosomes not involved in the reorganization. This phenomenon is known as the InterChromosomal Effect (ICE) [52]. For example, an aneuploidy of sex chromosomes might affect the segregation of an autosome, or the presence of a translocation could interfere with the segregation of chromosomes that are not involved in the rearrangement.

This review is aimed at summarizing FISH studies concerning sperm aneuploidy evaluated in infertile men with a normal somatic karyotype, including those affected by systematic sperm defects and in carriers of somatic chromosome abnormalities.

\section{INFERTILE MEN WITH A NORMAL KARYOTYPE}

Sperm aneuploidies were evaluated by FISH analysis in order to explore the possibility that meiosis in infertile men with normal karyotypes is prone to errors of nondisjunction. Several putative male risk factors for sperm aneuploidy have been described, including advanced age, cancer chemotherapy, suicide attempts by the use of high-dose diazepam, cigarette smoking, exposure to air pollution [53], chronic hepatitis $C$ virus infection [54], and recently even emotional stress [55]. Although the effect of hormones on meiotic segregation has been poorly investigated, a link has been reported between gonadal failure (demonstrated by a high serum follicle-stimulating hormone level) and the occurrence of sperm chromosome aneuploidies [56, 57]. An emerging field of research regards the potential effect of a toxic chemical present in the environment on reproductive disfunction. FISH studies on the sperm of men exposed to pesticides, including xenoestrogens, have yielded conflicting results [58]; however, recent studies indicate that persistent organohalogen pollutants may contribute to changes in $\mathrm{Y}$ - and X-chromosome-bearing sperm, determined by two-color FISH, of exposed populations [59].

Several studies have already verified that patients with poor semen quality and a normal $46, \mathrm{XY}$ karyotype show an increase in sperm disomy and diploidy rates $[2,18,60]$. The first report on this topic was performed by Moosani et al. [61] who studied men with OAT by using the human spermhamster oocyte fusion system and FISH for chromosomes 1, 12 and the sex chromosomes. A significant increase in the frequency of chromosome 1 and of XY disomies was found. Since then, many groups have confirmed that the frequency of sperm aneuploidy in 46, XY infertile men is approximately three times higher than in control donors [3]. Most of these studies concluded that there was an increase risk of chromosomal aneuploidies in cases of severe OAT $[4,10$, $11,62,63]$. Looking separately at each sperm parameter, the association of both severe oligozoospermia and teratozoospermia with sperm aneuploidy is generally accepted $[4,12,14,64-66]$. Regarding sperm morphology, macrocephalic, multinucleated, multiflagellated sperm appear to be at very high risk of aneuploidy [15, 17, 67-69]. Some asthenozoospermia studies have been performed to explore whether reduced sperm motility could be associated with increased sperm disomy and diploidy rates in infertile patients [12, 70-72]. Unfortunately it was difficult to isolate a large group of men with asthenozoospermia only, since this condition is often concomitant with oligo and/or teratozoospermia. Collodel et al. [13], examining a large population of patients stratified in groups according to motility parameter, observed that asthenozoospermia could be associated with altered sperm chromosome segregation. Increased rates of non disjunction for chromosomes 18, X and $\mathrm{Y}$ have also been demonstrated in sperm from infertile patients that had been identified as normal by strict morphology: normal morphology was not considered to be an absolute indicator for the selection of genetically normal sperm [73].

Looking at this issue from another perspective, altered meiotic segregation, leading to the production of diploidy and sex chromosomes disomy, has also been described in sperm from patients with genitourinary infections or recovered genitourinary infections [74, 75], from patients with varicocele $[18,76]$ and patients who underwent orchidopexy for unilateral or bilateral cryptorchidism during childhood [19]. It seems that any perturbation of spermatogenesis may cause an increased risk of aneuploid spermatozoa. Infertile males with poor sperm quality produce cytogenetically abnormal spermatozoa despite a normal karyotype as the result of an altered intra-testicular environment that negatively affects the mechanisms controlling chromosome segregation during cell division, as also noted by Calogero et al. [77].

An increase in sperm aneuploidy is undoubtedly involved in the outcome of ART. Increased total sperm aneuploidy rates were found to be associated with lower implantation and pregnancy rates and higher rates of miscarriage in patients undergoing ICSI [78]. A report from Bonduelle et al. [79] on prenatal diagnoses carried out on 1568 fetuses conceived by ICSI, showed a significant enhancement in de novo chromosomal anomalies of $1.58 \%$ of them, while only $0.45 \%$ of de novo abnormalities were found in the normal 
population. De novo sex chromosomal anomalies alone accounted for $0.63 \%$ of prenatally tested ICSI fetuses, compared to $0.19 \%$ in the normal population. This increased incidence of chromosomal abnormalities was related to sperm concentration and motility. Another study [80] reports the results of prenatal cytogenetic analysis performed in 71 fetuses conceived by ICSI: nine (12.7\%) chromosomal aberrations were detected, including two cases of $47, \mathrm{XXY}$, four cases involving a 45, $\mathrm{X}$ cell line and three cases of autosomal trisomies. Six cases involving a sex chromosome abnormality were found to be of paternal origin.

Aran et al. [62] have shown that patients with meiotic disorders and increased diploidy frequencies $(0.53 \%$ vs 0.25 $\%$ in controls) also had increased miscarriage rates after ICSI (33.3\% vs $7.1 \%$ in cases with normal meiosis) suggesting a direct involvement of abnormal spermatozoa in cases of recurrent miscarriage of presumably paternal origin [4].

Several sets of data indicate that moderate, albeit significant, increase in a given type of sperm disomy is related to an increase of aneuploidy in offspring. Some fathers of children with Down syndrome of paternal origin were affected by higher frequencies of chromosome 21 disomy in spermatozoa [81]. Paternal origin of trisomy 21, following ICSI procedure, was demonstrated by the analysis of two polymorphic microsatellite markers [82]. FISH studies explored sex chromosomes aneuploidy in sperm from men who fathered, by natural conception, children with Turner syndrome [83] and Klinefelter syndrome [84] highlighting a significant increase in XY disomy and sexnull sperm. A high level of nullisomy was also detected in sperm from a severely oligoasthenozoospermic man who produced, by ICSI, a 45, X abortus [85].

\section{Systematic Genetic Sperm Defects}

This section concerns the current literature related to FISH studies in spermatozoa with genetic sperm defects such as "globozoospermia", "DFS", "PCD", "detached tail", "absence of fibrous sheath" and defects of possible genetic origin recently described and characterized by an abnormally elongated midpiece and the presence of multiple axonemes and alternatively the absence of axoneme and outer dense fibers (ODF) or the absence of fibrous sheath in the principal piece.

\section{Globozoospermia}

Globozoospermia is a rare, yet severe disorder leading to male infertility that was first properly described by Schirren et al. [23] using electron microscopy. This uncommon alteration is characterized by $100 \%$ round headed sperm totally lacking an acrosome. These spermatozoa also show multiple defects involving the absence a of post-acrosomal sheath, and maturation defects such as persistence of cytoplasmic droplets surrounding the head or the midpiece, coiled flagella often with disorganized mitochondria and abnormal chromatin structure [86].

In 1992, Singh [87] distinguished two types of globozoospermia: type I is characterized by a complete absence of acrosome and consequently of acrosomal content, so these spermatozoa are totally unable to penetrate the zona pellucida; type II shows some acrosomal covering with a conical nucleus, sometimes embedded in large cytoplasmic residues, indicating secondary degenerative changes, and in this case infertility is caused by subsequent poor motility. Most of the papers, based on describing this morphology, regard type I globozoospermia.

It is noteworthy that in globozoospermic cells the chromatin compaction appears to be disturbed, in particular poor condensation and DNA fragmentation [88] were observed. Moreover, apoptosis, immaturity and necrosis have been detected by TEM [41]. On the contrary, other studies reported an association between globozoospermia and an abnormally condensed chromatin and overmaturity [86]. Taken together, the described chromatin alterations could also influence meiotic segregation, consequently impairing ICSI outcome. FISH studies, reporting meiotic segregation in sperm affected by the globozoospermia defect are shown in Table 1. Many authors have reported high aneuploidy frequency of autosomes 13, 15, 16, 18, and 21 $[33,34,37,39,41,89]$ and sex chromosomes [33, 36, 41], whereas other researches have not confirmed such an increased aneuploidy rate $[35,88,90]$.

Family incidence has been reported in men suffering from acrosomal aplasia, and a mono or polygenic origin has been suggested but not proven [20]. Over the past few years, knockout studies have identified several male infertility candidate genes, including some gene that alters sperm head morphology. In particular, the HIV-1 Rev-binding protein (Hrb) [91], Casein Kinase II alpha' isoform (Csnk2a2) [92], the Golgi-associated PDZ-and coiled coil motif-containing protein (GOPC) [93] and a protein interacting with $C$ kinase (PICK1) [94] are of particular interest, due to phenotypes in null mutant mice that are very similar to human globozoospermia. Regarding the pathogenesis of human globozoospermia, Dam et al. [95] reported a first description of an involved gene, describing a family with three affected brothers, in whom they identified a homozygous mutation in the spermatogenesis-specific gene SPATA 16.

Until the advent of ICSI, patients with this type of disorder were considered sterile. The first live birth by ICSI from globozoospermic sperm was reported by Lundin et al. [96], thus, if the inability to penetrate the oocytes is bypassed, fertilization could take place. Since then, numerous reports have described successful attempts to achieve either fertilization and pregnancy following ICSI with globozoospermic cells [86]. However, a low fertilization rate of globozoospermic sperm was observed and fertilization seems to be improved by the addition of a calcium ionophore. Using this method Rybouchkin et al. [90] reported a pregnancy in a couple with complete fertilization failure due to globozoospermia defect associated with deficient oocyte activation ability. Later, this system was successfully applied in other cases of globozoospermia [97-99].

\section{Dysplasia of the Fibrous Sheath (DFS)}

The denomination DFS was introduced by Chemes et al. [27] and it identifies major alterations in the fibrous sheath (FS). Most spermatozoa affected by this defect show rigid, short, thick, and/or irregular tails and 95 to $100 \%$ are immotile. Ultrastructural studies have highlighted that, despite general maturity of the head region, the axonemal components are generally disorganized and embedded in 
Table 1. FISH Studies of Disomy and Diploidy in Spermatozoa with Round Head Genetic Sperm Defect

\begin{tabular}{|c|c|c|c|c|c|c|c|c|c|c|c|c|c|c|c|}
\hline \multirow{2}{*}{ Studies } & \multicolumn{14}{|c|}{ Chromosomes Disomy \% } & \multirow{2}{*}{$\begin{array}{c}\text { Diploidy } \\
\%\end{array}$} \\
\hline & 1 & 7 & 8 & 9 & 12 & 13 & 15 & 16 & 18 & 21 & $\mathbf{X}+\mathbf{Y}$ & $\mathbf{X X}$ & YY & $\mathbf{X Y}$ & \\
\hline $\begin{array}{c}\text { Carrell et al. } \\
\text { [33] } \\
\text { (2 siblings) }\end{array}$ & & & & & & $\begin{array}{l}0.7 \\
0.3\end{array}$ & & & $\begin{array}{c}0 \\
0.2\end{array}$ & $\begin{array}{l}0.6 \\
3.0\end{array}$ & & $\begin{array}{l}0.6 \\
0.4\end{array}$ & $\begin{array}{l}0 \\
0\end{array}$ & $\begin{array}{c}12.1 \\
0\end{array}$ & \\
\hline $\begin{array}{c}\text { Morel } \text { et al. } \\
\quad[37] \\
(2 \text { cases })\end{array}$ & & $\begin{array}{l}0.259 \\
0.099\end{array}$ & & $\begin{array}{l}0.199 \\
0.139\end{array}$ & & $\begin{array}{l}0.390 \\
0.078\end{array}$ & & & $\begin{array}{l}0.021 \\
0.039\end{array}$ & $\begin{array}{l}0.390 \\
0.058\end{array}$ & & $\begin{array}{c}0 \\
0.019\end{array}$ & $\begin{array}{l}0.042 \\
0.079\end{array}$ & $\begin{array}{l}0.148 \\
0.079\end{array}$ & $\begin{array}{l}0.876 \\
0.304\end{array}$ \\
\hline $\begin{array}{c}\text { Viville et al. } \\
\text { [35] }\end{array}$ & 0 & & & & & & & & & & & 0 & 0 & 0 & 0.1 \\
\hline $\begin{array}{c}\text { Carrell et al. } \\
{[34]} \\
(2 \text { sibling })\end{array}$ & & & & & & $\begin{array}{l}0.40 \\
0.32\end{array}$ & $\begin{array}{l}4.03 \\
0.58\end{array}$ & & $\begin{array}{l}0.74 \\
0.74\end{array}$ & $\begin{array}{l}0.40 \\
0.14\end{array}$ & & $\begin{array}{l}* \\
\text { * }\end{array}$ & $\begin{array}{l}* \\
\text { * }\end{array}$ & & \\
\hline $\begin{array}{c}\text { Ditzel et al. } \\
{[39]^{\$}}\end{array}$ & & & & & & 6.0 & & 7.0 & & 4.0 & & & & & 1 \\
\hline $\begin{array}{c}\text { Vicari et al. } \\
{[88]}\end{array}$ & & & 0 & & 0 & & & & 0 & & & 0 & 0.16 & 0 & \\
\hline $\begin{array}{l}\text { Martin et al. } \\
\quad[36]\end{array}$ & 0.09 & & & & & & 0.13 & & & 0.19 & & 0.12 & 0.07 & 0.38 & 0.21 \\
\hline $\begin{array}{c}\text { Moretti et al. } \\
{[41]} \\
\text { (2 cases) }\end{array}$ & & & & & & & & & $\begin{array}{l}0.052 \\
0.078\end{array}$ & & $\begin{array}{l}0.364 \\
0.364\end{array}$ & $\begin{array}{l}0.104 \\
0.052\end{array}$ & $\begin{array}{l}0.026 \\
0.026\end{array}$ & $\begin{array}{l}0.234 \\
0.286\end{array}$ & $\begin{array}{l}0.599 \\
0.494\end{array}$ \\
\hline $\begin{array}{c}\text { Shi \& Martin } \\
{[2]} \\
\text { (Controls) }\end{array}$ & 0.20 & & & & 0.17 & 0.08 & 0.06 & & 0.06 & 0.07 & 0.13 & 0.03 & 0.05 & 0.05 & \\
\hline $\begin{array}{l}\text { Collodel \& } \\
\text { Moretti, [179] } \\
\text { Controls) }\end{array}$ & & & & & & & & & 0.10 & & 0.25 & 0.06 & 0.05 & 0.14 & 0.28 \\
\hline
\end{tabular}

*Chromosome X aneuploidy \%: 0.46; Chromosome Y aneuploidies\%: 0.52, ${ }^{\circ}$ Chromosome X aneuploidy \%: 0.52; Chromosome Y aneuploidies\%: $0.60 . \$ 100$ spermatozoa were evaluated in each sample. In the other published studies the number of cells scored for each patient was between 3,716 [35] and 30,145 [36].

hyperplasic FS material, invading the whole space of the short tail. Mitochondria are not assembled as a periaxonemal helix. The familial incidence of DFS suggests a genetic origin of the defect [100-102]. In recent years, extensive work has been carried out on the protein composition of the FS. Numerous proteins of the FS have been isolated and characterized [103]. Two of these proteins, members of AKAP family (A-kinase anchor proteins), AKAP3 and AKAP4, have been studied extensively in human spermatozoa and in knockout mice showing sperm with short flagella and disorganized FS [20, 104-106].

Regarding FISH studies (Table 2), Rives et al. [40] described elevated frequencies of XX, YY disomies and diploidies in spermatozoa from an individual affected by the DFS defect, whereas Viville et al. [35], examining sperm from a patient with short flagella syndrome, detected a normal meiotic segregation for the analyzed chromosomes. In recent papers $[38,43]$ triple-color FISH for chromosomes $18, \mathrm{X}$ and $\mathrm{Y}$ was used to analyze spermatozoa from 13 patients with DFS, diagnosed by TEM. A high incidence of numeric disturbances in sperm chromosome constitution, mainly diploidy and sex chromosomal aneuploidies, was observed (Table 2).

Fertility prognosis in these cases has been addressed with microinjection of DFS sperm, which has resulted in fair to good fertilization. Successful ICSI treatments using DFS sperm have been reported in the literature [102, 107-109]; an accurate review of ICSI outcome in those cases was performed by Chemes and Rawe [20].

\section{Primary Ciliary Dyskinesia (PCD)}

PCD, also known as immotile cilia syndrome (ICS), is a condition of sperm immotility and recurrent respiratory tract infections in which all ciliary and flagellar functions are involved [110]. Approximately 50\% of ICS/PCD patients have alterations in the visceral rotation (situs viscerum inversus) with dextrocardia, corresponding to the Kartagener syndrome. Under light microscopy, sperm tails appear morphologically normal but stiff. TEM analysis revealed the characteristic features of this defect, such as missing outer or inner or both dynein arms, the absence of one or two central microtubules or radial spokes, transposed microtubules, and a lack of axoneme [110-113].

To date, many genes have been found to be mutated in human PCD: some of them encode for dynein protein arm subunits (DNAI1, DNAI2, DNAH5, DNAHI1) [114-116]. A new gene, kintoun (ktu), was found mutated in PCD where both outer and inner dynein arms were missing or defective in the axoneme [117].

Current information on meiotic segregation is scarce (Table 2) and includes an increased frequency of XX, YY disomy and diploidy that has been observed in spermatozoa 
Table 2. FISH Studies of Disomy and Diploidy in Spermatozoa with Different Genetic Sperm Defects Affecting the Tail

\begin{tabular}{|c|c|c|c|c|c|c|}
\hline \multirow{2}{*}{ Studies } & \multicolumn{5}{|c|}{ Chromosomes Disomy \% } & \multirow{2}{*}{ Diploidy \% } \\
\hline & 18 & $\mathbf{X}+\mathbf{Y}$ & $\mathbf{X X}$ & YY & $\mathbf{X Y}$ & \\
\hline \multirow{12}{*}{$\begin{array}{l}\text { Baccetti } \text { et al. }[38] \\
\text { DFS (12 cases) }\end{array}$} & 0.092 & 0.530 & 0.069 & 0.092 & 0.369 & 0.946 \\
\hline & 0.240 & 0.490 & 0.190 & 0.090 & 0.210 & 0.890 \\
\hline & 0.050 & 0.205 & 0.025 & 0.103 & 0.077 & 0.465 \\
\hline & 0.024 & 0.270 & 0.098 & 0.049 & 0.123 & 0.344 \\
\hline & 0.232 & 0.408 & 0.146 & 0.116 & 0.146 & 0.554 \\
\hline & 0.120 & 0.670 & 0.050 & 0.170 & 0.450 & 0.430 \\
\hline & 0.050 & 0.470 & 0.040 & 0.130 & 0.300 & 0.630 \\
\hline & 0.213 & 0.355 & 0.047 & 0.023 & 0.285 & 0.593 \\
\hline & 0.086 & 0.259 & 0.065 & 0.086 & 0.108 & 0.172 \\
\hline & 0.088 & 0.176 & 0.022 & 0.022 & 0.132 & 0.595 \\
\hline & 0.091 & 0.306 & 0.061 & 0.061 & 0.184 & 0.858 \\
\hline & 0.130 & 0.733 & 0.131 & 0.157 & 0.445 & 0.575 \\
\hline Rives et al. [40] & 0.06 & & 0.40 & 0.51 & 0.13 & 0.16 \\
\hline DFS ( 2 cases) & 0.01 & & 0.18 & 0.16 & 0.13 & 0.17 \\
\hline $\begin{array}{c}\text { Moretti \& Collodel [43] } \\
\text { DFS }\end{array}$ & 0.098 & 0.569 & 0.198 & 0.074 & 0.297 & 0.669 \\
\hline $\begin{array}{l}\text { Rives et al. [40] } \\
\text { Kartagener }\end{array}$ & 0.080 & & 0.220 & 0.190 & 0.130 & 0.460 \\
\hline $\begin{array}{c}\text { Moretti \& Collodel [43] } \\
\text { PCD }\end{array}$ & 0.140 & 0.340 & 0.200 & 0.040 & 0.100 & 0.460 \\
\hline Absence of fibrous sheath & 0.100 & 0.270 & 0.060 & 0.040 & 0.170 & 0.280 \\
\hline Detached tails* & 0.00 & 0.054 & 0.054 & 0 & 0 & 0.16 \\
\hline $\begin{array}{c}\text { Moretti et al. }[32] \\
\text { Composed sperm defects }\end{array}$ & 0.09 & 0.18 & 0.03 & 0.03 & 0.12 & 0.24 \\
\hline $\begin{array}{l}\text { Collodel \& Moretti, [179] } \\
\text { (Controls) }\end{array}$ & 0.10 & 0.25 & 0.06 & 0.05 & 0.14 & 0.28 \\
\hline
\end{tabular}

*1855 nuclei analyzed, since only a few sperm heads were found in the ejaculate.

In the other studies the number of cells scored for each patient was between 4,374 [43] and 10,000 [40].

from a patient affected by Kartagener syndrome associated with situs viscerum inversus, chronic sinusitis and bronchiectasis [40]. Moretti and Collodel [43] reported a case of PCD where FISH data highlighted that the frequency of chromosome 18 disomy was normal, whereas the values of sex chromosomes disomy and diploidies were higher compared with those from controls.

Regarding reproductive potential, only one live birth has been reported after in vitro fertilization (IVF) using spermatozoa with no progressive motility [118] due to Kartagener syndrome. Fertilization [119], pregnancies [118, $120,121]$, and live birth $[119,120]$ have been reported in the case of PCD, also using testicular sperm from men with Kartagener/immotile cilia syndrome [122, 123].

\section{Detached Tail}

Sperm with the "detached tail" defect show heads of normal structure but a deficient post-nuclear region, lacking basal plate and implantation fossa. Tails are broken off at different levels of the midpiece. The detached tail defect originates in the testis and may also occur in the epididymis. If the separation occurs in the testis, the heads are probably phagocyted by Sertoli cells [124] and in vitro fertilization is impossible. Many authors have reported cases of "acephalic spermatozoa" or "decapitated spermatozoa", indicating abnormalities of the head-neck attachment at various levels of the tail $[26,125,126]$. Proteins such as centrin, pericentrin, $\gamma$-tubulin, speriolin and that recognized by mitotic protein monoclonal antibody-2 have been localized in the sperm centrosome and connecting piece regions, however their significance in the pathogenesis of this syndrome is not clear [127-129]. The human Hook1 gene has been identified as a candidate gene for male infertility since mutation of this gene causes teratozoospermia and decapitation defects [130].

The only case of FISH analysis for chromosomes 18, X and Y (Table 2), performed in decondensed sperm nuclei of such a defect, revealed values of disomy and diploidies comparable to those obtained from the sperm of fertile men [43].

Two cases regarding the possibility of ART attempts must be distinguished. Acephalic forms are predominant in most reported cases, making any attempt at ART impossible. In another variant of the syndrome, acephalic forms are less frequent and spermatozoa with abnormal head-midpiece alignment are predominant [20]. In this case attempts to 
achieve pregnancies have been made using the ICSI method. In the first report by Chemes et al. [125], oocytes reached the pronuclear stage but failed to undergo syngamy and cleavage. This phenomenon was also observed by Rawe et al. [131] in four ICSI cycles with two chemical pregnancies followed by preclinical miscarriage and by Saias-Magnan et al. [132] who observed little embryo fragmentation but no pregnancy. A malfunction of the sperm centriole has been claimed as an explanation of this phenomenon [131] and recently a decreased proteasomal activity in human spermatozoa with defective centriolar/ pericentriolar structures has also been observed [133], suggesting an important role of sperm proteasomes in zygotic development. A successful birth after ICSI using detached tail sperm has recently been obtained [134].

\section{Composed Sperm Defects of Possible Genetic Origin}

These sperm defects are apparently very rare and TEM is needed to characterize them. They probably originate during spermiogenesis and share some typical features, such as a generally well structured sperm head, an abnormally elongated midpiece and the presence of supplementary axonemes. In a case described in the literature by only two groups [30,31], a total absence of fibrous sheath was observed in the principal piece region, whereas in the other case a total absence of the axoneme and ODF in $95 \%$ of principal pieces at the tail level was highlighted [32, 135]. FISH analysis was performed in only one case for each defect and a normal incidence of diploidy and disomy for 18, $\mathrm{X}$ and $\mathrm{Y}$ chromosomes was observed (Table 2) $[32,43]$.

In these cases no ICSI attempts were performed, although Rawe et al. [136] obtained oocytes fertilization but no pregnancies by means of ICSI in two infertile patients with abnormal organization of sperm mitochondrial helixes and severe asthenoteratozoospermia.

\section{MEN WITH ALTERED SOMATIC KARYOTYPE}

\section{Robertsonian Traslocations}

Robertsonian translocations are characterized by the centric fusion of two acrocentric chromosomes resulting in a 45 chromosome karyotype. When the chromosomes pair during meiosis, the translocated chromosomes and their homologues do so as a trivalent. The resulting gametes can be chromosomally normal or aneuploid with an extra or missing chromosome q arm. Robertsonian carriers with fusions between chromosomes 13 ad 14 are very common among infertile men.

FISH studies recently reviewed by Martin [3] have shown that the meiotic segregation of Robertsonian translocation carriers presented a mean of $15 \%$ unbalanced spermatozoa. All Robertsonian translocations have relatively similar segregation behaviours, despite the participation of different acrocentric chromosomes.

Another aspect to be considered is the possiblility of ICE, which seems to affect $58 \%$ of Robertsonian translocation carriers [3]. The effects of ICE on the meiotic segregation of sex chromosomes and autosomes has been broadly investigated [12, 48, 137-139] and the results have generally suggested that ICE is restricted to translocation carriers with abnormal semen parameters [12, 48, 51].
Some studies concerning preimplantation genetic diagnosis (PGD) in the case of Robertsonian translocation carriers have reported that a high frequency of embryos show aneuploidy [140,141], whereas others have not found this effect $[142,143]$.

In summary, the risk of chromosomal imbalance at prenatal diagnosis is quite low. The final outcome can be a spontaneous abortion or a chromosomally abnormal conceptus, depending on the chromosome involved. Many of these unbalanced chromosomal patterns are not viable since only $1-2 \%$ of paternally derived Robertsonian translocations are unbalanced at prenatal diagnosis [144].

\section{Reciprocal Translocations}

Reciprocal translocations are an exchange of chromosome material between the arms of any two chromosomes, and the risks of chromosomally unbalanced offspring from male carriers are higher than those from Robertsonian translocations. During meiosis I, translocated chromosomes and their homologues are associated as a quadrivalent and the segregation of the chromosomes involved in this quadrivalent give rise to different frequencies of unbalanced sperm.

The average frequency of chromosomally unbalanced spermatozoa in reciprocal translocation carriers is $50 \%$, it is strongly dependent on the chromosomes involved in the individual translocation and in the break-point position, and it may be slightly increased as a result of a small ICE [2]. As observed by Vozdova et al. [145], studying sperm from three male carriers of two different translocations involving chromosomes 11 and 18, the incidence of chromosomally unbalanced or aneuploid gametes varies in the individual translocation carriers even if the same chromosomes are included in the translocation. Martin [3] summarized FISH studies about chromosome segregations in 99 reciprocal translocation heterozygotes, showing a wide range in the frequency of unbalanced gametes, from $37 \%$ to $91 \%$. In most reciprocal translocation carriers, alternate segregants are the most common, occurring at approximately $44 \%-51 \%$; adjacent 1 segregants have a frequency of $16 \%-40 \%$; adjacent 2 segregants are less common with a mean frequency of 9\%; and 3:1 segregants occur at a mean frequency of $11 \%$ with a wide range of $2 \%-40 \%$ [2]. Reciprocal translocation X-autosomes have been reported to be a direct genetic risk factor for spermatogenetic maturation arrest. For example, an unusual reciprocal $\mathrm{X}$-autosome 11 translocation was recently found in an infertile man with azoospermia [146]. It is also known that $\mathrm{Y}$-autosome translocation is a rare condition, associated with azoospermia [147] and Pinho et al. [148] found a de novo $\mathrm{t}(\mathrm{Y} ; 1)(\mathrm{q} 12 ; \mathrm{q} 12)$ balanced reciprocal translocation with the loss of the heterochromatic region of chromosome 1 that caused the unpairing of sex chromosomes followed by meiosis I arrest, apoptotic degeneration of germ cells and azoospermia. A correlation between poor sperm quality, increased sperm aneuploidy rates and the presence of a reciprocal translocation is well documented $[12,48,50]$.

Many studies, reviewed by Shi and Martin [2], have analyzed ICE in reciprocal translocation carriers, demonstrating that the presence of ICE varies greatly among the studied chromosomes. In particular, the high frequency 
of sperm diploidies detected by FISH indicates an incomplete process of meiosis leading to immature sperm cells with double nuclei, as observed by TEM, or with a double chromosome set. So far, the increase in diploid sperm has been detected in carriers of balanced reorganizations [4], underling the pivotal role of diploid sperm in the origin of triploidy, causing pregnancy wastage.

An analysis of meiotic segregation patterns and aneuploidy in the spermatozoa of a father and son with a $\mathrm{t}(4 ; 5)(\mathrm{p} 15.1 ; \mathrm{p} 12)$ and the prediction of the individual probability rate for unbalanced progeny at birth have also been carried out; the risk assessment for unfavorable pregnancy outcomes was predicted as $1.6 \%$ for unbalanced progeny at birth and about $30 \%$ for miscarriage. These figures may be used as guidelines for the genetic counseling of families with similar reciprocal translocations [149]. However, some translocations have increased risks of imbalance and survival, and all have serious consequences of mental and physical handicaps. A number of fetuses with unbalanced segregation of reciprocal translocations has been reported after ICSI $[150,151]$. PGD plays a pivotal role in these cases in order to avoid the implantation of chromosomally abnormal embryos.

\section{Inversions}

Paracentric and pericentric inversions have been described in almost all human chromosomes.

Paracentric inversion (PAI) is a rearrangement involving two breaks within the same chromosome arm, followed by the reinsertion of the chromosome segment after a 180 degree rotation. PAI are one of the most common forms of chromosome polymorphism found in nature, with a suggested incidence ranging from $0.1 \%$ to $0.5 \%$ in the human population. PAI is associated with a very low risk of recombination disequilibrium, as reported and reviewed by Vialard et al. [152]. A new strategy based on FISH assay has been developed using multiple bacterial artificial chromosome probes to identify chromosomal breakpoints and meiotic products in human sperm $[153,154]$.

Most researchers agree on the absence of ICE in PAI. To the best of our knowledge, no publications have reported a relationship between PAI and altered sperm parameters, although Ichioka et al. [155] have described a case in which PAI of the short arm of chromosome 7 was associated with azoospermia.

Pericentric inversions are structural chromosomal abnormalities resulting from two breaks within the same chromosome, one on each side of the centromere, followed by a 180 degree rotation and reunion of the inverted segment. Anton et al. [156] reported a variable production of unbalanced gametes $(0-38 \%)$ in inversion carriers, which implies heterogeneous behavior of the inversion. This variability seems to be directly related to the size of the inversion, indicating that the production of recombinant gametes in an inversion carrier would not be relevant when the inverted segment is small. Pericentric inversion of chromosomes 9 and 2 are considered to be normal variants of karyotype [157]. However, some evidence reported in the literature has shown a possible involvement of pericentric chromosome 9 inversion in unrelated and related infertile men [158, 159]. Baccetti et al. [160] observed a severe asthenozoospermia in two unrelated heterozygous carriers of a pericentric inversion of chromosome 9, explained by the existence of the DFS sperm defect. Semen samples from 18 male carriers of chromosome 9 inversion were recently analysed. Five out of 18 patients were azoospermic, sperm concentration was normal in nine patients and progressive motility was in the normal range in only two patients. The presence of apoptosis was observed by TEM analysis. FISH data have shown an increased incidence of diploidy [161].

The reproductive fitness of inversion carriers could also be compromised by the occurrence of ICE; the literature reports several sperm segregation studies in inversion carriers, reviewed by Anton et al. [156], but none of them found a significant occurrence of ICE. On the contrary, an increase in aneuploidy in sperm nuclei was demonstrated in a man who was heterozygous for pericentric chromosome 9 inversion [162].

\section{Numerical Chromosome Anomalies}

Sex chromosome aneuploidies are the most common chromosome abnormalities observed in the general male population, predominantly in Klinefelter syndrome (47, XXY) and 47, XYY [163].

Patients with Klinefelter syndrome, or mosaic 47,XXY/46,XY, generally show greatly impaired spermatogenesis with severe oligozoospermia or azoospermia. Mosaicism is a condition in which tissues of genetically different types occur in the same organism; the most common mosaic karyotypes are $45, \mathrm{X} / 46, \mathrm{XX}$ and $45, \mathrm{X} / 46, \mathrm{XY}$; another frequent mosaicism is $46, \mathrm{XY} / 47 \mathrm{XXY}$.

With the aid of modern infertility treatment, technologies such as testicular sperm extraction and ICSI, it is possible for azoospermic 47, XXY patients to father a child. Sperm chromosome studies have demonstrated that only normal germ cells seem to enter into meiosis and at least some XXY cells can reach the primary spermatocyte stage [4]. FISH studies performed in several men with $47, \mathrm{XXY} / 46, \mathrm{XY}$ have revealed higher sperm aneuploidy frequencies compared to controls; sperm aneuploidy frequencies in non mosaic Klinefelter men varied from $2 \%$ to $25 \%$ [2]. Arnedo et al. [164] studied by FISH sperm aneuploidy in fathers of Klinefelter syndrome offspring. In $53 \%$ of the examined cases, the additional $\mathrm{X}$ chromosome was of paternal origin. The fathers of paternally transmitted Klinefelter syndrome also showed a significantly higher frequency of XY disomy sperm compared to fathers of the maternal origin group.

Males with an extra Y chromosome are mostly fertile. However, as in the general male population, semen parameters in these men may vary from normozoospermia to severe oligozoospermia [4]. Early meiotic studies in 47,XYY patients suggested that the extra $\mathrm{Y}$ chromosome might be lost in the pre-meiotic stages, but in some cases the presence of one $\mathrm{X}$ and the two $\mathrm{Y}$ chromosomes was detected during prophase I as an univalent plus a YY bivalent.

Sperm chromosome studies by FISH in 47,XYY males were first performed by Han et al. [165]. Since then, other authors have shown a moderately increased frequency of sex chromosome abnormalities in this kind of spermatozoa [166$168]$, but they have found ICE in a lower number of men [166]. 
A case of an oligoasthenoteratozoospermic 47, XYY male has recently been described. TEM analysis showed an elevated percentage of sperm apoptosis associated with a higher incidence of sex chromosomes disomy and diploidy (specifically 1818XY, indicating a nondisjunction in the first meiotic division (Fig. 1a) than the values observed in controls [169]. Sperm apoptosis has been supposed to be the cause of spermatogenetic impairment due to the persistence of an extra Y chromosome $[167,170]$.

In addition, a high rate of sex chromosomal and autosomal aneuploidy has been observed in sperm and preimplantation embryos from nonmosaic 47,XYY males. The offspring of this category of patients may be at an increased risk of chromosomal abnormalities, and therefore PGD can be suggested to these patients [171].

Numerical autosomal alterations, such as monosomies and trisomies, are not viable and their products are eliminated during pregnancy or in the perinatal period. Chromosomally abnormal conceptions surviving to term include mainly trisomy 13 (probability of survival at birth $2.8 \%$ ), 18 (probability of survival of $5.4 \%$ ) and 21 (probability of survival of 22.1\%). Males with trisomy 21 are azoospermic or show severe oligozoospermia. To our knowledge, meiotic studies have only been performed in one case, and in most metaphase I figures $(88.5 \%)$ the extra chromosome was present as a univalent [4].

Morphological and meiotic spermatogenetic impairment has also been described in men showing a mosaic 46XY/47XY+18 karyotype [172, 173] and altered semen quality. Evidence of a generalized perturbation of the meiotic mechanism leading to an increased risk of producing offspring with aneuploidy was highlighted.

\section{DISCUSSION}

Since infertile males, who are candidates for ICSI, could be carriers of sperm aneuploidies, the study of the chromosomal constitution of their spermatozoa is of great interest. The natural selection process of spermatozoa does not occur in ICSI and the risk of injecting abnormal sperm may cause a higher incidence of chromosomal anomalies [174], thus greatly contributing to pregnancy wastage. The increase in prenatal chromosomal abnormalities in ICSI pregnancies, mainly involving sex chromosomes [79] or the novo complex intra chromosomal rearrangement [175], has led to the debate regarding the origin of abnormalities and the risk of men prone to aneuploidy. Although some conceptions with numerically altered chromosomal karyotype are maternally derived, studies identify the father as the origin of many of these abnormalities.

The advent of FISH in decondensed sperm nuclei has offered an interesting approach to evaluate aneuploidies directly in male gametes. FISH sperm analysis has been revealed to be the fastest and easiest method, particularly to measure the proportion of unbalanced gametes produced by individuals with structural chromosomal rearrangments. Its use has become very common worldwide and it is even recommended to be routinely incorporated in the genetic screening offered prior to PGD.

The problem of the possible presence of aneuploidy in sperm from infertile men should be seriously considered in
ART, due to the documented risk of transmission of chromosomal imbalance to offspring.

We are aware that it is difficult to consider FISH sperm analysis as a routine examination, but the best candidates for a meiotic study should be carefully identified. Regarding infertile males with normal karyotype, we recommend FISH screening in cases of severe impairment of at least one semen parameter. Gianaroli et al. [176] have suggested the inclusion of FISH sperm analysis in preliminary tests offered to infertile couples, mainly in the case of repeated IVF failure. Sanchez-Castro et al. [177] recently reported that sperm aneuploidy and diploidy screening seems to be an effective prognostic tool that would be useful in the reproductive genetic counseling of infertile couples, especially in oligozoospermic patients.

Particular attention should be payed to systematic sperm defects, for which further studies should be performed to implement the lack of data regarding the incidence of aneuploidies in that kind of anomalies. Moreover, besides the risk of aneuploidy transmission, there could also be a real possibility of transmitting unknown mutations and causing genetic sperm defects. Regarding infertile males with altered karyotype, Anton et al. [178] affirmed that Robertsonian translocation carriers would not obtain much benefit from particular segregation studies because they have a nonrandom homogeneous segregation pattern with a clearly preferential alternate segregation, leading to a mean of $84 \%$ normal/balanced gametes. In reciprocal translocation carriers, the production of normal/balanced gametes would be in a small range of around $35 \%-50 \%$. Only some specific cases with particular cytogenetic characteristics would deserve further consideration. In inversion carriers, the convenience of FISH sperm studies should be considered in relation to the dimensions of the inverted segment. FISH sperm studies should be recommended [178] only in cases in which the risk of producing unbalanced gametes varies with significant reproductive consequences (carriers of inverted segments involving $\sim 40 \%-50 \%$ of the chromosome). Structural reorganization carriers with significant increases in aneuploidies would have two genetic risks: those derived from the segregation of the rearranged chromosomes, and ICE. ICE studies in sperm could be helpful in the genetic reproductive advice for carriers involved in a PGD program, mainly because the frequent presence of this phenomenon in carriers, the absence of conclusive data about the characteristics of the reorganizations related to ICE, and its controversial effect at the embryo level.

In cases of positive results, a supplementary aneuploid PGD screening should be incorporated in the conventional PGD for structural anomalies [178]. As reported by Egozcue et al. [4], prenatal diagnosis is highly recommended in embryos obtained when the male partner carries a sex chromosome abnormality; although PGD would be desirable in these cases, the risk of loosing the embryos and the lower pregnancy rates obtained after PGD preclude its use when gestation may already be very difficult to obtain.

In general, all patients should be informed of the risks of producing chromosomally abnormal sperm and children; they should undergo appropriate genetic analyses and informed consent should be obtained before proceeding to 
ICSI and it is important to discuss the option of PGD with the couple.

\section{REFERENCES}

[1] De Kretser DM. Male infertility. Lancet 1997; 349: 787-90.

[2] Shi Q, Martin RH. Aneuploidy in human spermatozoa: FISH analysis in men with constitutional chromosomal abnormalities, and in infertile men. Reproduction 2001; 121: 655-6.

[3] Martin RH. Cytogenetic determinants of male infertility. Hum Reprod Update 2008; 14: 379-90.

[4] Egozcue S, Blanco J, Vendrell JM, et al. Human male infertility: chromosome anomalies, meiotic disorders, abnormal spermatozoa and recurrent abortion. Hum Reprod Update 2000; 6: 93-105.

[5] Rudak E, Jacobs PA, Yanagimachi R. Direct analysis of the chromosome constitution of human spermatozoa. Nature 1978; 274: 911-3.

[6] Martin RH, Balkan W, Burns K, Rademaker AW, Lin CC, Rudd NL. The chromosome constitution of 1000 human spermatozoa. Hum Genet 1983; 63: 305-9.

[7] Brandriff B, Gordon L, Ashworth L, et al. Chromosomes of human sperm: variability among normal individuals. Hum Genet 1985; 70 : 18-24.

[8] Templado C, Márquez C, Munné S, et al. An analysis of human sperm chromosome aneuploidy. Cytogenet Cell Genet 1996; 74: 194-200.

[9] Miharu N, Best RG, Young SR. Numerical chromosome abnormalities in spermatozoa of fertile and infertile men detected by fluorescence in situ hybridization. Hum Genet 1994; 93: 502-6.

[10] Pang MG, Hoegerman SF, Cuticchia AJ, et al. Detection of aneuploidy for chromosomes 4, 6, 7, 8, 9, 10, 11, 12, 13, 17, 18, 21, X and $\mathrm{Y}$ by fluorescence in-situ hybridization in spermatozoa from nine patients with oligoasthenoteratozoospermia undergoing intracytoplasmic sperm injection. Hum Reprod 1999; 14: 1266-73.

[11] Ushijimal C, Kumasako Y, Kihaile PE, Hirotsuru K, Utsunomiya T. Analysis of chromosomal abnormalities in human spermatozoa using multi-colour fluorescence in-situ hybridization. Hum Reprod 2000; 15 : 1107-11.

[12] Vegetti W, Van Assche E, Frias A, et al. Correlation between semen parameters and sperm aneuploidy rates investigated by fluorescence in-situ hybridization in infertile men. Hum Reprod 2000; 15: 351-65.

[13] Collodel G, Capitani S, Baccetti B, Pammolli A, Moretti E. Sperm aneuploidies and low progressive motility. Hum Reprod 2007; 22: 1893-8.

[14] Templado C, Hoang T, Greene C, Rademaker A, Chernos J, Martin R. Aneuploid spermatozoa in infertile men: teratozoospermia. Mol Reprod Dev 2002; 61: 200-4.

[15] In't Veld PA, Broekmans FJ, de France HF, Pearson PL, Pieters MH, van Kooij RJ. Intracytoplasmic sperm injection (ICSI) and chromosomally abnormal spermatozoa. Hum Reprod 1997; 12: 752-4.

[16] Gole LA, Wong PF, Ng PL, Wang XQ, Ng SC, Bongso A. Does sperm morphology play a significant role in increased sex chromosomal disomy? A comparison between patients with teratozoospermia and OAT by FISH. J Androl 2001; 22: 759-63.

[17] Lewis-Jones I, Aziz N, Seshadri S, Douglas A, Howard P. Sperm chromosomal abnormalities are linked to sperm morphologic deformities. Fertil Steril 2003; 79: 212-5.

[18] Baccetti B, Bruni E, Capitani S, et al. Studies on varicocele III: ultrastructural sperm evaluation and $18, \mathrm{X}$ and $\mathrm{Y}$ aneuploidies. J Androl 2006; 27: 94-101.

[19] Moretti E, Di Cairano G, Capitani S, Scapigliati G, Baccetti B, Collodel G. Cryptorchidism and semen quality: a TEM and molecular study. J Androl 2007; 28: 194-9.

[20] Chemes HE, Rawe VY. Sperm pathology: a step beyond descriptive morphology. Origin, characterization and fertility potential of abnormal sperm phenotypes in infertile men. Hum Reprod Update 2003; 5: 405-28.

[21] Baccetti B, Capitani S, Collodel G, et al. Genetic sperm defects and consanguinity. Hum Reprod 2001; 16: 1365-71.

[22] Baccetti B, Burrini AG, Collodel G, et al. Crater defect in human spermatozoa. Gamete Res 1989; 22: 249-55.

[23] Schirren CG, Holstein AF, Schirren C. Uber die morphogenese rundkopfiger spermatozoen des menschen. Andrologia 1971; 3: 117-25.

[24] Baccetti B, Burrini AG, Collodel G, Piomboni P, Renieri T. A "miniacrosome" sperm defect causing infertility in two brothers. J Androl 1991; 12: 104-11.
[25] Holstein AF, Schill WB, Breucker H. Dissociated centriole development as a cause of spermatid malformation in man. J Reprod Fertil 1986; 78: 719-25

[26] Baccetti B, Burrini AG, Collodel G, et al. Morphogenesis of the decapitated and decaudated sperm defect in two brothers. Gamete Res 1989; 23: 181-8.

[27] Chemes HE, Brugo S, Zanchetti F, Carrere C, Lavieri JC. Dysplasia of the fibrous sheath: an ultrastructural defect of human spermatozoa associated with sperm immotility and primary sterility. Fertil Steril 1987; 48: 664-9.

[28] Rossman CM, Forrest JB, Lee RM, Newhouse AF, Newhouse MT. The dyskinetic cilia syndrome; abnormal ciliary motility in association with abnormal ciliary ultrastructure. Chest 1981; 80: 860-5.

[29] Baccetti B, Burrini AG, Maver A, Pallini V, Renieri T. "9 + 0" immotile spermatozoa in an infertile man. Andrologia 1979; 11: 43743.

[30] Ross A, Christie S, Kerr MG. An electron microscope study of a tail abnormality in spermatozoa from a subfertile man. J Reprod Fertil 1971; 24: 99-103.

[31] Baccetti B, Bruni E, Gambera L, Moretti E, Piomboni P. An ultrastructural and immunocytochemical study of a rare genetic sperm tail defect that causes infertility in humans. Fertil Steril 2004; 82: 4638.

[32] Moretti E, Pascarelli NA, Federico MG, Renieri T, Collodel G. Abnormal elongation of midpiece, absence of axoneme and outer dense fibers at principal piece level, supernumerary microtubules: a sperm defect of possible genetic origin? Fertil Steril 2008; 90: 1201.e3-8.

[33] Carrell DT, Emery BR, Liu L. Characterization of aneuploidy rates, protamine levels, ultrastructure, and functional ability of round-headed sperm from two siblings and implications for intracytoplasmic sperm injection. Fertil Steril 1999; 71: 511-6.

[34] Carrell DT, Wilcox AL, Udoff LC, Thorp C, Campbell B. Chromosome 15 aneuploidy in the sperm and conceptus of a sibling with variable familial expression of round-headed sperm syndrome. Fertil Steril 2001; 76: 1258-60.

[35] Viville S, Mollard R, Bach ML, Falquet C, Gerlinger P, Warter S. Do morphological anomalies reflect chromosomal aneuploidies?: case report. Hum Reprod 2000; 15: 2563-6.

[36] Martin RH, Greene C, Rademaker AW. Sperm chromosome aneuploidy analysis in a man with globozoospermia. Fertil Steril 2003; 79: $1662-4$

[37] Morel F, Douet-Guilbert N, Moerman A, et al. Chromosome aneuploidy in the spermatozoa of two men with globozoospermia. Mol Hum Reprod 2004; 10: 835-8.

[38] Baccetti B, Collodel G, Gambera L, Moretti E, Serafini F, Piomboni P. Fluorescence in situ hybridization and molecular studies in infertile men with dysplasia of the fibrous sheath. Fertil Steril 2005; 84: 123-9.

[39] Ditzel N, El-Danasouri I, Just W, Sterzik K. Higher aneuploidy rates of chromosomes 13,16, and 21 in a patient with globozoospermia. Fertil Steril 2005; 84: 217-8.

[40] Rives N, Mousset-Simeon N, Mazurier S, Mace B. Primary flagellar abnormality is associated with an increased rate of spermatozoa aneuploidy. J Androl 2005; 26: 61-9.

[41] Moretti E, Collodel G, Scapigliati G, Cosci I, Sartini B, Baccetti B. Round head sperm defect. Ultrastructural and meiotic segregation study. J Submicrosc Cytol Pathol 2005; 37: 297-303.

[42] Collodel G, Moretti E. Sperm morphology and aneuploidies: defects of supposed genetic origin. Andrologia 2006; 38: 208-15.

[43] Moretti E, Collodel G. Three cases of genetic defects affecting sperm tail: a FISH study. J Submicrosc Cytol Pathol 2006; 38: 137-41.

[44] Kjessler B. Karyotype, Meiosis and spermatogenesis in a sample of men attending an infertility clinic. Monogr Hum Genet 1966; 2: 1-93.

[45] Chandley AC, Edmond P, Christie S, et al. Cytogenetics and infertility in man. I. Karyotype and seminal analysis: results of a five-year survey of men attending a subfertility clinic. Ann Hum Genet 1975; 39: 23154.

[46] Van Assche E, Bonduelle M, Tournaye H, et al. Cytogenetics of infertile men. Hum Reprod 1996; 11(Suppl 4): 1-24; discussion 25-26.

[47] Rousseaux S, Chevret E, Monteil M, et al. Meiotic segregation in males heterozygote for reciprocal translocations: analysis of sperm nuclei by two and three colour fluorescence in situ hybridization. Cytogenet Cell Genet 1995; 71: 240-6.

[48] Pellestor F, Imbert I, Andreo B, Lefort G. Study of the occurrence of interchromosomal effect in spermatozoa of chromosomal 
rearrangement carriers by fluorescence in-situ hybridization and primed in-situ labelling techniques. Hum Reprod 2001; 16: 1155-64.

[49] Baccetti B, Capitani S, Collodel G, Estenoz M, Gambera L, Piomboni P. Infertile spermatozoa in a human carrier of robertsonian translocation 14;22. Fertil Steril 2002; 78: 1127-30.

[50] Baccetti B, Bruni E, Collodel G, et al. 10, 15 reciprocal translocation in an infertile man: ultrastructural and fluorescence in-situ hybridization sperm study: case report. Hum Reprod 2003; 18: 2302-8.

[51] Baccetti B, Collodel G, Marzella R, et al. Ultrastructural studies of spermatozoa from infertile males with Robertsonian translocations and 18, X, Y aneuploidies. Hum Reprod 2005; 20: 2295-300.

[52] Lejeune J. Les concéquences méiotique des remaniements chromosomique. Ann Genet 1965; 8: 9-10.

[53] Rubes J, Vozdova M, Robbins WA, Rezacova O, Perreault SD, Wyrobek AJ. Stable variants of sperm aneuploidy among healthy men show associations between germinal and somatic aneuploidy. Am J Hum Genet 2002; 70: 1507-19.

[54] Moretti E, Federico MG, Giannerini V, Collodel G. Sperm ultrastructure and meiotic segregation in a group of patients with chronic hepatitis B and C. Andrologia 2008; 40: 286-91.

[55] Collodel G, Moretti E, Fontani V, et al. Effect of emotional stress on sperm quality. Indian J Med Res 2008; 128: 254-61.

[56] Levron J, Aviram-Goldring A, Madgar I, Raviv G, Barkai G, Dor J. Sperm chromosome abnormalities in men with severe male factor infertility who are undergoing in vitro fertilization with intracytoplasmic sperm injection. Fertil Steril 2001; 76: 479-84.

[57] Faure AK, Aknin-Seifer I, Frerot G, et al. Predictive factors for an increased risk of sperm aneuploidies in oligo-asthenoteratozoospermic males. Int J Androl 2007; 30: 153-62.

[58] Härkönen K. Pesticides and the induction of aneuploidy in human sperm. Cytogenet Genome Res 2005; 111: 378-83.

[59] Tiido T, Rignell-Hydbom A, Jönsson BA, et al. INUENDO. Impact of PCB and p,p'-DDE contaminants on human sperm Y:X chromosome ratio: studies in three European populations and the Inuit population in Greenland. Environ Health Perspect 2006 ; 114: 718-24.

[60] Gianaroli L, Magli MC, Cavallini G, et al. Frequency of aneuploidy in sperm from patients with extremely severe male factor infertility. Hum Reprod 2005; 20: 2140-52.

[61] Moosani N, Pattinson HA, Carter MD, Cox DM, Rademaker AW, Martin RH. Chromosomal analysis of sperm from men with idiopathic infertility using sperm karyotyping and fluorescence in situ hybridization. Fertil Steril 1995; 64: 811-7.

[62] Aran B, Blanco J, Vidal F, et al. Screening for abnormalities of chromosomes $\mathrm{X}, \mathrm{Y}$, and 18 and for diploidy in spermatozoa from infertile men participating in an in vitro fertilization-intracytoplasmic sperm injection program. Fertil Steril 1999; 72: 696-701.

[63] Nishikawa N, Murakami I, Ikuta K, Suzumori K. Sex chromosomal analysis of spermatozoa from infertile men using fluorescence in situ hybridization. J Assist Reprod Genet 2000; 17: 97-102.

[64] Martin RH, Rademaker AW, Greene C, et al. A comparison of the frequency of sperm chromosome abnormalities in men with mild, moderate, and severe oligozoospermia. Biol Reprod 2003; 69: 535-9.

[65] Machev N, Gosset P, Viville S. Chromosome abnormalities in sperm from infertile men with normal somatic karyotypes: teratozoospermia. Cytogenet Genome Res 2005; 111: 352-7.

[66] Miharu N. Chromosome abnormalities in sperm from infertile men with normal somatic karyotypes: oligozoospermia. Cytogenet Genome Res 2005; 111: 347-51.

[67] Benzacken B, Gavelle FM, Martin-Pont B, et al. Familial sperm polyploidy induced by genetic spermatogenesis failure: case report. Hum Reprod 2001; 16: 2646-51.

[68] Devillard F, Metzler-Guillemain C, Pelletier R, et al. Polyploidy in large-headed sperm: FISH study of three cases. Hum Reprod 2002; 17 : 1292-8.

[69] Perrin A, Morel F, Moy L, Colleu D, Amice V, De Braekeleer M. Study of aneuploidy in large-headed, multiple-tailed spermatozoa: case report and review of the literature. Fertil Steril 2008; 90: 1201.e13-7.

[70] Hristova R, Ko E, Greene C, Rademaker A, Chernos J, Martin R. Chromosome abnormalities in sperm from infertile men with asthenoteratozoospermia. Biol Reprod 2002; 66: 1781-3.

[71] Bernardini LM, Calogero AE, Bottazzi C, et al. Low total normal motile count values are associated with increased sperm disomy and diploidy rates in infertile patients. Int J Androl 2005; 28: 328-36.
[72] Rives NM. Chromosome abnormalities in sperm from infertile men with normal somatic karyotypes: asthenozoospermia. Cytogenet Genome Res 2005; 111: 358-62.

[73] Ryu HM, Lin WW, Lamb DJ, Chuang W, Lipshultz LI, Bischoff FZ. Increased chromosome $\mathrm{X}, \mathrm{Y}$, and 18 nondisjunction in sperm from infertile patients that were identified as normal by strict morphology: implication for intracytoplasmic sperm injection. Fertil Steril 2001; 76: 879-83.

[74] Collodel G, Baccetti B, Capitani S, Moretti E. Necrosis in human spermatozoa. I. Ultrastructural features and FISH study in semen from patients with uro-genital infections. J Submicrosc Cytol Pathol 2005; 37: 67-73.

[75] Moretti E, Baccetti B, Capitani S, Collodel G. Necrosis in human spermatozoa. II. Ultrastructural features and FISH study in semen from patients with recovered uro-genital infections. J Submicrosc Cytol Pathol 2005; 37: 93-8.

[76] Finkelstein S, Mukamel E, Yavetz H, Paz G, Avivi L. Increased rate of nondisjunction in sex cells derived from low-quality semen. Hum Genet 1998; 102: 129-37.

[77] Calogero AE, Burrello N, De Palma A, Barone N, D'Agata R, Vicari E. Sperm aneuploidy in infertile men. Reprod Biomed Online 2003; 6: 310-7.

[78] Burrello N, Vicari E, Shin P, et al. Lower sperm aneuploidy frequency is associated with high pregnancy rates in ICSI programmes. Hum Reprod 2003; 18: 1371-6.

[79] Bonduelle M, Van Assche E, Joris H, et al. Prenatal testing in ICSI pregnancies: incidence of chromosomal anomalies in 1586 karyotypes and relation to sperm parameters. Hum Reprod 2002; 17: 2600-14.

[80] Van Opstal D, Los FJ, Ramlakhan S, et al. Determination of the parent of origin in nine cases of prenatally detected chromosome aberrations found after intracytoplasmic sperm injection. Hum Reprod 1997; 12: 682-6.

[81] Blanco J, Gabau E, Gómez D, et al. Chromosome 21 disomy in the spermatozoa of the fathers of children with trisomy 21 , in a population with a high prevalence of Down syndrome: increased incidence in cases of paternal origin. Am J Hum Genet 1998; 63: 1067-72.

[82] Bartels I, Schlösser M, Bartz UG, Pauer HU. Paternal origin of trisomy 21 following intracytoplasmic sperm injection (ICSI). Hum Reprod 1998; 13: 3345-6.

[83] Martínez-Pasarell O, Templado C, Vicens-Calvet E, Egozcue J, Nogués C. Paternal sex chromosome aneuploidy as a possible origin of Turner syndrome in monozygotic twins: case report. Hum Reprod 1999; 14: 2735-8.

[84] Eskenazi B, Wyrobek AJ, Kidd SA, et al. Sperm aneuploidy in fathers of children with paternally and maternally inherited Klinefelter syndrome. Hum Reprod 2002; 17: 576-83.

[85] Tang SS, Gao H, Robinson WP, Ho Yuen B, Ma S. An association between sex chromosomal aneuploidy in sperm and an abortus with $45, \mathrm{X}$ of paternal origin: possible transmission of chromosomal abnormalities through ICSI. Hum Reprod 2004; 19: 147-51.

[86] Dam AH, Feenstra I, Westphal JR, Ramos L, van Golde RJ, Kremer JA. Globozoospermia revisited. Hum Reprod Update 2007; 13: 63-75.

[87] Singh G. Ultrastructural features of round-headed human spermatozoa. Int J Fertil 1992; 37: 99-102.

[88] Vicari E, Perdichizzi A, De Palma A, Burrello N, D'Agata R, Calogero AE. Globozoospermia is associated with chromatin structure abnormalities: case report. Hum Reprod 2002; 17: 2128-33.

[89] Carrell DT, Emery BR, Wilcox AL, et al. Sperm chromosome aneuploidy as related to male factor infertility and some ultrastructure defects. Arch Androl 2004; 50: 181-5.

[90] Rybouchkin A, Dozortsev D, Pelinck MJ, De Sutter P, Dhont M. Analysis of the oocyte activating capacity and chromosomal complement of round-headed human spermatozoa by their injection into mouse oocytes. Hum Reprod 1996; 11: 2170-5.

[91] Kang-Decker N, Mantchev GT, Juneja SC, McNiven MA, van Deursen JM. Lack of acrosome formation in Hrb-deficient mice. Science 2001; 294: 1531-3.

[92] Xu X, Toselli PA, Russell LD, Seldin DC. Globozoospermia in mice lacking the casein kinase II alpha' catalytic subunit. Nat Genet 1999; 23: 118-21.

[93] Yao R, Ito C, Natsume Y, et al. Lack of acrosome formation in mice lacking a Golgi protein, GOPC. Proc Natl Acad Sci USA 2002; 99: 11211-6.

[94] Xiao N, Kam C, Shen C, et al. PICK1 deficiency causes male infertility in mice by disrupting acrosome formation. J Clin Invest 2009; 119(4): 302-12. 
[95] Dam AH, Koscinski I, Kremer JA, et al. Homozygous mutation in SPATA16 is associated with male infertility in human globozoospermia. Am J Hum Genet 2007; 81: 813-20.

[96] Lundin K, Sjogren A, Nilsson L, Hamberger L. Fertilization and pregnancy after intracytoplasmic microinjection of acrosomeless spermatozoa. Fertil Steril 1994; 62: 1266-7.

[97] Dirican EK, Isik A, Vicdan K, Sozen E, Suludere Z. Clinical pregnancies and livebirths achieved by intracytoplasmic injection of round headed acrosomeless spermatozoa with and without oocyte activation in familial globozoospermia: case report. Asian J Androl 2008; 10: 332-6.

[98] Kyono K, Nakajo Y, Nishinaka C, et al. A birth from the transfer of a single vitrified-warmed blastocyst using intracytoplasmic sperm injection with calcium ionophore oocyte activation in a globozoospermic patient. Fertil Steril 2008; Nov 29.

[99] Tejera A, Mollá M, Muriel L, Remohí J, Pellicer A, De Pablo JL. Successful pregnancy and childbirth after intracytoplasmic sperm injection with calcium ionophore oocyte activation in a globozoospermic patient. Fertil Steril 2008; 90: 1202.e1-5.

[100] Baccetti B, Burrini A, Pallini V, Renieri T, Rosati F, Menchini Fabris GF. The short tailed human spermatozoa. Ultrastructural alterations and dynein absence. J Submicrosc Cytol Pathol 1975; 7 : 349-59.

[101] Alexandre C, Bisson JP, David G. Total asthenospermia with an ultrastructural anomaly of the flagellum in two sterile brothers. J Gynecol Obstet Biol Reprod 1978; 7: 31-8.

[102] Chemes HE, Olmedo SB, Carrere C, et al. Ultrastructural pathology of the sperm flagellum: association between flagellar pathology and fertility prognosis in severely asthenozoospermic men. Hum Reprod 1998; 13: 2521-6.

[103] Eddy EM, Toshimori K, O’ Brien DA. Fibrous sheath of mammalian spermatozoa. Microsc Res Tech 2003; 61: 103-15.

[104] Miki K, Willis WD, Brown PR, Goulding EH, Fulcher KD, Eddy EM. Targeted disruption of the AKAP4 gene causes defects in sperm flagellum and motility. Dev Biol 2002; 248: 331-42.

[105] Turner RM, Musse MP, Mandal A, et al. Molecular genetic analysis of two human sperm fibrous sheath proteins, AKAP4 and AKAP3, in men with dysplasia of the fibrous sheath. J Androl 2001; 22: 302-15.

[106] Baccetti B, Collodel G, Estenoz M, Manca D, Moretti E, Piomboni P. Gene deletions in an infertile man with sperm fibrous sheath dysplasia. Hum Reprod 2005; 20: 2790-4.

[107] Stalf T, Sanchez R, Kohn FM, et al. Pregnancy and birth after intracytoplasmic sperm injection with spermatozoa from a patient with tail stump syndrome. Hum Reprod 1995; 10: 2112-4.

[108] Olmedo SB, Nodar F, Chillik C, Chemes HE. Successful intracytoplasmic sperm injection with spermatozoa from a patient with dysplasia of the fibrous sheath and chronic respiratory disease. Hum Reprod 1997; 12: 1497-9.

[109] Olmedo SB, Rawe VY, Nodar FN, Galaverna GD, Acosta AA, Chemes HE. Pregnancies established through intracytoplasmic sperm injection (ICSI) using spermatozoa with dysplasia of fibrous sheath. Asian J Androl 2000; 2: 125-30.

[110] Afzelius BA. A human syndrome caused by immotile cilia. Science 1976; 193: 317-9.

[111] Escalier D, David G. Pathology of the cytoskeleton of the human sperm flagellum: axonemal and peri-axonemal anomalies. Biol Cell 1984; 50: 37-52.

[112] Chemes HE, Morero JL, Lavieri JC. Extreme asthenozoospermia and chronic respiratory disease: a new variant of the immotile cilia syndrome. Int J Androl 1990; 13: 216-22.

[113] Baccetti B, Burrini AG, Capitani C, et al. Notulae seminologicae. 1. New combinations of Kartagener's syndrome. Andrologia 1993; 25: 325-9.

[114] Chodhari R, Mitchison HM, Meeks M. Cilia, primary ciliary dyskinesia and molecular genetics. Paediatr Respir Rev 2004; 5: 6976.

[115] Failly M, Saitta A, Muñoz A, et al. DNAI1 mutations explain only 2\% of primary ciliary dykinesia. Respiration 2008; 76: 198-204.

[116] Loges NT, Olbrich H, Fenske L, et al. DNAI2 mutations cause primary ciliary dyskinesia with defects in the outer dynein arm. Am J Hum Genet 2008; 83: 547-58.

[117] Omran H, Kobayashi D, Olbrich H, et al. Ktu/PF13 is required for cytoplasmic pre-assembly of axonemal dyneins. Nature 2008; 456: 611-6.

[118] Kay VJ, Irvine DS. Successful in-vitro fertilization pregnancy with spermatozoa from a patient with Kartagener's syndrome: case report. Hum Reprod 2000; 15: 135-8.
[119] Papadimas J, Tarlatzis BC, Bili H, et al. Therapeutic approach of immotile cilia syndrome by intracytoplasmic sperm injection: a case report. Fertil Steril 1997; 67: 562-5.

[120] von Zumbusch A, Fiedler K, Mayerhofer A, Jessberger B, Ring J, Vogt HJ. Birth of healthy children after intracytoplasmic sperm injection in two couples with male Kartagener's syndrome. Fertil Steril 1998; 70: 643-6.

[121] Peeraer K, Nijs M, Raick D, Ombelet W. Pregnancy after ICSI with ejaculated immotile spermatozoa from a patient with immotile cilia syndrome: a case report and review of the literature. Reprod Biomed Online 2004; 9: 659-63.

[122] Cayan S, Conaghan J, Schriock ED, Ryan IP, Black LD, Turek PJ. Birth after intracytoplasmic sperm injection with use of testicular sperm from men with Kartagener/immotile cilia syndrome. Fertil Steril 2001; 76: 612-4.

[123] Kaushal M, Baxi A. Birth after intracytoplasmic sperm injection with use of testicular sperm from men with Kartagener or immotile cilia syndrome. Fertil Steril 2007; 88: 497.e9-11.

[124] Chemes HE, Carizza C, Scarinci F, Brugo S, Neuspiller N, Schwarsztein L. Lack of a head in human spermatozoa from sterile patients: a syndrome associated with impaired fertilization. Fertil Steril 1987; 47: 310-6.

[125] Chemes HE, Puigdomenech ET, Carizza C, Olmedo SB, Zanchetti F, Hermes R. Acephalic spermatozoa and abnormal development of the head-neck attachment: a human syndrome of genetic origin. Hum Reprod 1999; 14: 1811-8.

[126] Toyama Y, Iwamoto T, Yajima M, Baba K, Yuasa S. Decapitated and decaudated spermatozoa in man, and pathogenesis based on the ultrastructure. Int J Androl 2000; 23: 109-15.

[127] Manandhar G, Schatten G. Centrosome reduction during Rhesus spermiogenesis: gamma-tubulin, centrin, and centriole degeneration. Mol Reprod Dev 2000; 56: 502-11.

[128] Porcu G, Mercier G, Boyer P, et al. Pregnancies after ICSI using sperm with abnormal head-tail junction from two brothers: Case report. Hum Reprod 2003; 18: 562-7.

[129] Goto M, Eddy EM. Speriolin is a novel spermatogenic cell-specific centrosomal protein associated with the seventh WD motif of Cdc20. J Biol Chem 2004; 279: 42128-38.

[130] Mendoza-Lujambio I, Burfeind P, Dixkens C, et al. The Hook1 gene is non-functional in the abnormal spermatozoon head shape (azh) mutant mouse. Hum Mol Genet 2002; 11: 1647-58.

[131] Rawe VY, Terada Y, Nakamura S, Chillik CF, Olmedo SB, Chemes HE. A pathology of the sperm centriole responsible for defective sperm aster formation, syngamy and cleavage. Hum Reprod 2002; 17 : 2344-9.

[132] Saïas-Magnan J, Metzler-Guillemain C, Mercier G, CarlesMarcorelles F, Grillo JM, Guichaoua MR. Failure of pregnancy after intracytoplasmic sperm injection with decapitated spermatozoa: case report. Hum Reprod 1999; 14: 1989-92.

[133] Rawe VY, Díaz ES, Abdelmassih R, et al. The role of sperm proteasomes during sperm aster formation and early zygote development: implications for fertilization failure in humans. Hum Reprod 2008; 23: 573-80

[134] Gambera L, Falcone P, Mencaglia L, et al. Intracytoplasmic sperm injection and pregnancy with decapitated sperm. Fertil Steril 2009; [Epub ahead of print].

[135] Sauvalle A, Le Bris C, Izard J. Supernumerary microtubules and prolongation of the middle piece in two infertile patients. Int $\mathbf{J}$ Fertil 1983; 28: 173-6.

[136] Rawe VY, Hermes R, Nodar FN, Fiszbajn G, Chemes HE. Results of intracytoplasmic sperm injection in two infertile patients with abnormal organization of sperm mitochondrial sheaths and severe asthenoteratozoospermia. Fertil Steril 2007; 88: 649-53.

[137] Blanco J, Egozcue J, Vidal F. Interchromosomal effects for chromosome 21 in carriers of structural chromosome reorganizations determined by fluorescence in situ hybridization on sperm nuclei. Hum Genet 2000; 106: 500-5

[138] Morel F, Roux C, Bresson JL. FISH analysis of the chromosomal status of spermatozoa from three men with 45,XY,der(13;14)(q10; q10) karyotype. Mol Hum Reprod 2001; 7: 483-8.

[139] Anton E, Blanco J, Egozcue J, Vidal F. Sperm FISH studies in seven male carriers of Robertsonian translocation $\mathrm{t}(13 ; 14)(\mathrm{q} 10 ; \mathrm{q} 10)$. Hum Reprod 2004; 19: 1345-51.

[140] Conn CM, Harper JC, Winston RM, Delhanty JD. Infertile couples with Robertsonian translocations: preimplantation genetic analysis of 
embryos reveals chaotic cleavage divisions. Hum Genet 1998; 102: $117-23$.

[141] Gianaroli L, Magli MC, Ferraretti AP, Tabanelli C, Trombetta C, Boudjema $\mathrm{E}$. The role of preimplantation diagnosis for aneuploidies. Reprod Biomed Online 2002; 4: 31-6.

[142] Scriven PN, Flinter FA, Braude PR, Ogilvie CM. Robertsonian translocations--reproductive risks and indications for preimplantation genetic diagnosis. Hum Reprod 2001; 16: 2267-73.

[143] Munné S. Analysis of chromosome segregation during preimplantation genetic diagnosis in both male and female translocation heterozygotes. Cytogenet Genome Res 2005; 111: 305-9.

[144] Boué A, Gallano P. A collaborative study of the segregation of inherited chromosome structural rearrangements in 1356 prenatal diagnoses. Prenat Diagn 1984; 45-67.

[145] Vozdova M, Oracova E, Horinova V, Rubes J. Sperm fluorescence in situ hybridization study of meiotic segregation and an interchromosomal effect in carriers of $\mathrm{t}(11 ; 18)$. Hum Reprod 2008; 23 : 581-8.

[146] Ishikawa T, Kondo Y, Yamaguchi K, et al. An unusual reciprocal Xautosome translocation in an infertile azoospermic man. Fertil Steril 2007; 88: 705.e15-7.

[147] Sasagawa I, Nakada T, Adachi Y, et al. Y-autosome translocation associated with azoospermia. Scand J Urol Nephrol 1993; 27: 285-8.

[148] Pinho MJ, Neves R, Costa $\mathrm{P}$, et al. Unique t(Y;1)(q12;q12) reciprocal translocation with loss of the heterochromatic region of chromosome 1 in a male with azoospermia due to meiotic arrest: a case report. Hum Reprod 2005; 20: 689-96.

[149] Wiland E, Midro AT, Panasiuk B, Kurpisz M. The analysis of meiotic segregation patterns and aneuploidy in the spermatozoa of father and son with translocation $\mathrm{t}(4 ; 5)(\mathrm{p} 15.1 ; \mathrm{p} 12)$ and the prediction of the individual probability rate for unbalanced progeny at birth. J Androl 2007; 28: 262-72.

[150] Baschat AA, Küpker W, al Hasani S, Diedrich K, Schwinger E. Results of cytogenetic analysis in men with severe subfertility prior to intracytoplasmic sperm injection. Hum Reprod 1996; 11: 330-3.

[151] Meschede D, Louwen F, Eiben B, Horst J. Intracytoplasmic sperm injection pregnancy with fetal trisomy $9 p$ resulting from a balanced paternal translocation. Hum Reprod 1997; 12: 1913-4

[152] Vialard F, Delanete A, Clement P, Simon-Bouy B, Aubriot FX, Selva J. Sperm chromosome analysis in two cases of paracentric inversion. Fertil Steril 2007; 87: 418.

[153] Bhatt S, Moradkhani K, Mrasek K, et al. Breakpoint characterization: a new approach for segregation analysis of paracentric inversion in human sperm. Mol Hum Reprod 2007; 13: 751-6.

[154] Bhatt S, Moradkhani K, Mrasek K, et al. Breakpoint mapping and complete analysis of meiotic segregation patterns in three men heterozygous for paracentric inversions. Eur J Hum Genet 2009; 17: 44-50.

[155] Ichioka K, Yoshimura K, Honda T, Takahashi A, Terai A. Paracentric inversion of chromosome 7(q22-31) associated with nonobstructive azoospermia. Fertil Steril 2005; 83: 455-6.

[156] Anton E, Vidal F, Egozcue J, Blanco J. Genetic reproductive risk in inversion carriers. Fertil Steril 2006; 85: 661-6.

[157] Gardner RJM, Sutherland GR. Chromosome abnormalities and genetic counselling, $3^{\text {rd }}$ ed. New York: Oxford University Press 2004.

[158] Boue J, Taillemite JL, Hazael-Massieux P, Leonard C, Boue A. Association of pericentric inversion of chromosome 9 and reproductive failure in ten unrelated families. Humangenetik 1975; 30: 217-24.

[159] Davalos IP, Rivas F, Ramos AL, Galaviz C, Sandoval L, Rivera H. $\operatorname{Inv}(9)(p 24 q 13)$ in three sterile brothers. Ann Genet 2000; 43: 51-4.

[160] Baccetti B, Collodel G, Crisà D, Moretti E, Piomboni P. Notulae seminologicae. 8. Ultrastructural sperm defects in two men, carriers of autosomal inversion. Andrologia 1997; 29: 277-82.
[161] Collodel G, Moretti E, Capitani S, et al. TEM, FISH and molecular studies in infertile men with pericentric inversion of chromosome 9. Andrologia 2006; 38: 122-7.

[162] Amiel A, Sardos-Albertini F, Fejgin MD, Sharony R, Diukman R, Bartoov B. Interchromosomal effect leading to an increase in aneuploidy in sperm nuclei in a man heterozygous for pericentric inversion (inv 9) and C-heterochromatin. J Hum Genet 2001; 46: 24550.

[163] Hook EB, Hamerton JL. In: Hook EB, Porter IH, Eds. Population Cytogenetics. New York: Academic Press 1997; p. 63.

[164] Arnedo N, Templado C, Sánchez-Blanque Y, Rajmil O, Nogués C. Sperm aneuploidy in fathers of Klinefelter's syndrome offspring assessed by multicolour fluorescent in situ hybridization using probes for chromosomes 6, 13, 18, 21, 22, X and Y. Hum Reprod 2006; 21 524-8.

[165] Han TH, Ford JH, Flaherty SP, Webb GC, Matthews CD. A fluorescent in situ hybridization analysis of the chromosome constitution of ejaculated sperm in a 47,XYY male. Clin Genet 1994; 45: 67-70.

[166] Shi Q, Martin RH. Multicolor fluorescence in situ hybridization analysis of meiotic chromosome segregation in a 47,XYY male and a review of the literature. Am J Med Genet 2000; 93: 40-6.

[167] Rives N, Milazzo JP, Miraux L, North MO, Sibert L, Macé B. From spermatocytes to spermatozoa in an infertile XYY male. Int J Androl 2005; 28: 304-10.

[168] Wong EC, Ferguson KA, Chow V, Ma S. Sperm aneuploidy and meiotic sex chromosome configurations in an infertile XYY male. Hum Reprod 2008; 23: 374-8.

[169] Moretti E, Anichini C, Sartini B, Collodel G. Sperm ultrastructure and meiotic segregation in an infertile 47, XYY man. Andrologia 2007; 39: 229-34.

[170] Milazzo JP, Rives N, Mousset-Siméon N, Macé B. Chromosome constitution and apoptosis of immature germ cells present in sperm of two 47,XYY infertile males. Hum Reprod 2006; 21: 1749-58.

[171] Gonzalez-Merino E, Hans C, Abramowicz M, Englert Y, Emiliani S Aneuploidy study in sperm and preimplantation embryos from nonmosaic 47,XYY men. Fertil Steril 2007; 88: 600-6.

[172] Collodel G, Cosci I, Pascarelli AN, Moretti E. Sperm ultrastructure and $18, \mathrm{X}, \mathrm{Y}$ aneuploidies in a man with a $46 \mathrm{XY}, 47 \mathrm{XY}+18$ mosaic karyotype: case report. J Assist Reprod Genet 2007; 24: 373-6.

[173] Perrin A, Douet-Guilbert N, Le Bris MJ, et al. Increased aneuploidy rates in spermatozoa of a male carrier of a trisomy 18 mosaicism. Int $\mathbf{J}$ Androl 2008; [Epub ahead of print]

[174] Aboulghar H, Aboulghar M, Mansour R, Serour G, Amin Y, Al-Inany $\mathrm{H}$. A prospective controlled study of karyotyping for 430 consecutive babies conceived through intracytoplasmic sperm injection. Fertil Steril 2001; 76: 249-53.

[175] Kasakyan S, Lohmann L, Aboura A, et al. De novo complex intra chromosomal rearrangement after ICSI: characterisation by BACs micro array -CGH. Mol Cytogenet 2008; 1: 27.

[176] Gianaroli L, Magli MC, Ferraretti AP. Sperm and blastomere aneuploidy detection in reproductive genetics and medicine. Histochem Cytochem 2005; 53: 261-7.

[177] Sánchez-Castro M, Jiménez-Macedo AR, Sandalinas M, Blanco J. Prognostic value of sperm fluorescence in situ hybridization analysis over PGD. Hum Reprod 2009; 24(6): 1516-21.

[178] Anton E, Vidal F, Blanco J. Role of sperm FISH studies in the genetic reproductive advice of structural reorganization carriers. Hum Reprod 2007; 22: 2088-92

[179] Collodel G, Moretti E. Morphology and meiotic segregation in spermatozoa from men of proven fertility. J Androl 2008; 29: 106-14. 